\title{
Measuring the health of people in places: A scoping review of OECD member countries
}

\author{
Emily T. Murray ${ }^{\text {a, }}$, Nicola Shelton ${ }^{a}$, Paul Norman ${ }^{\text {b }}$, Jenny Head ${ }^{\text {a }}$ \\ ${ }^{\text {a }}$ University College London, Research Department of Epidemiology and Public Health, London, UK \\ ${ }^{\mathrm{b}}$ University of Leeds, School of Geography, Leeds, UK
}

\section{A B S T R A C T}

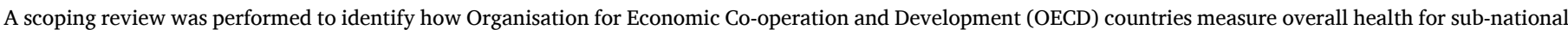

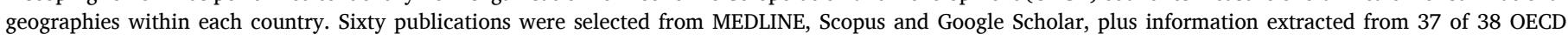

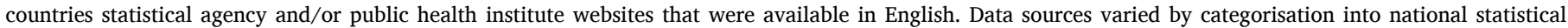

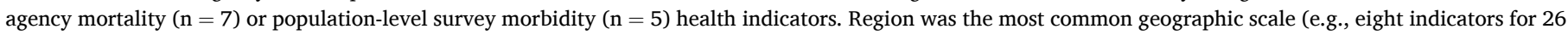

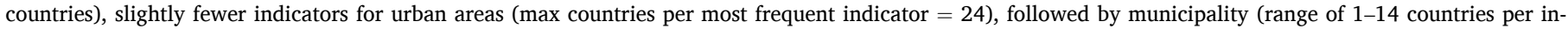

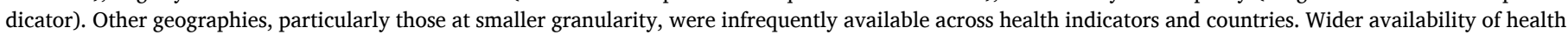
indicators at smaller, and non-administrative, geographies is needed to explore the best way to measure comparative population health in local areas.

\section{Introduction}

It is well known that health varies by geography. Across countries, within countries, and even within local geographies, people with better and worse health tend to cluster in different locations. These geographic health divides are longstanding and universal (Bambra, 2016).

Whether these spatial patterns of health reflect causal processes or are just an artefact of people with similar health states tending to live in the same places, is debated in the scientific literature (Jokela, 2015). What is important on a practical level is being able to document and measure the overall level and distribution of health among a population in a geographical area. This ability to measure what we call here 'health in a place' is important for multiple reasons: research theory and methods, health provision planning at local, national and cross-national levels, social care, welfare spending and community services; to name a few. Arguments have also been made that the health of people in places should be viewed as a social and economic asset in its own right (Marshall et al., 2018).

Before we can assess which places are healthy or unhealthy, we need to define what we mean by good or bad health (i.e., which health indicators). The use of mortality to represent health in a place is longstanding, largely underpinned by legal processes for death registration (Declich and Carter, 1994). However, analysis of mortality has its drawbacks. For example, mortality only reflects health processes that lead to death (Parrish, 2010). Many other non-mortality-based health indicators, or combinations of said indicators, have been proposed for measuring public health (Parrish, 2010; WHO, 2018b). Unfortunately, access to consistent and comparable, local level morbidity data remains elusive.

There are also core theoretical considerations of what is a healthy or unhealthy population (Etches et al., 2006; Parrish, 2010), dominated by whether definitions should only include normal biological functioning or be expanded to include complete wellbeing (Bickenbach, 2015). In practice, philosophy tends to give way to considerations of health indicators being useful to organisations for population health monitoring, policy formation and evaluation (Bilheimer, 2010; Etches et al., 2006). For example, the World Health Organisation (WHO) defines health as a "state of complete physical, mental and social well-being and not merely the absence of disease or infirmity (WHO, 1948)." Yet the official WHO core health indicators contain many disease-specific indicators (WHO, 2018a), with a new classification system introduced for the 'measurement' of health, called The International Classification of Functioning, Disability and Health, endorsed in 2001 by all Member States (WHO, 2018c). Other methods used by organisations to try to meld these different priorities into a core set of required health indicators has been to develop formal assessment tools (Becker et al., 2010), expert panels (Freitas et al., 2018) and co-produced health indices (Costa et al., 2019b; Medicine, 1998; Shandera, 2014). The reality being that many different organisations collect many different population-level health indicators for many different reasons.

\footnotetext{
* Corresponding author. Department of Epidemiology \& Population Health, University College London, 1-19 Torrington Place, London, WC1E 7HB, UK.

E-mail address: emily.murray@ucl.ac (E.T. Murray).
} 
When measuring health in a place, an added complication is which geographic boundary should be used to define and delineate 'place'. Here too the philosophical and conceptual struggle to meld with the practical. Generally, neighbourhood effects researchers would prefer smaller, and 'bespoke' spatial boundary definitions, to reflect that many health-related socio-spatial processes occur at local levels that vary by individual perception and space usage (Petrovic et al., 2020). Some researchers recently argued for taking into consideration larger political and economic structures when investigating links between health and place (Bambra et al., 2019). The latter would align better with the needs of national and international requirements (e.g., public health monitoring, health service planning, etc.) (Etches et al., 2006). We must acknowledge that the mechanisms that influence health of people in places, and collective population health relationships with higher-level social and economic inequalities, are most likely occurring at multiple geographic scales simultaneously (Petrovic et al., 2020).

Whether current health indicator data at sub-national geographies is available to meet the needs of these multiple parties is currently unknown. Generally, ranges of health indicators at smaller geographies are frequently compared within countries through 'Health Profiles' (Hill et al., 2010). When expanding to cross-country comparisons of health in a place, only a few projects have summarised cross-European health indicator data at a single sub-national geography (Gray et al., 2012; Wilkinson et al., 2008, 2009). The most notable project being the Indicateurs sante régionaux d'Europe (ISARE) project, which in its third iteration focused on the health of regions in 23 European countries (Wilkinson et al., 2009). Health comparisons are frequently made between countries in the EU and other countries with similar developed economies and/or health systems. We therefore believe a comprehensive review requires coverage of all current members of the Organisation for Economic Co-operation and Development (OECD, 2021).

The approach of this review is therefore to summarise what health indicator data are available currently to any of the parties that would require the data for their purpose(s). We focus on data availability for the past 10 years, as even though new health indicator data are being collected and derived at regular intervals from many different sources, e. g., Eurostat (2021b), important population-level morbidity data are only collected every 10 years for some countries, e.g. United Kingdom (ONS, 2021). We focus on publicly listed data sources, which includes sensitive data that is described in a source, as data are not really available if most potential users cannot reasonably find evidence of its existence.

\section{Methods}

The objective of this review was to provide an overview, not a synthesis, of health indicator availability at sub-national geographies for countries in the OECD. Therefore, we followed a scoping review approach, specifically the four-stage approach of Arksey and O'Malley (Arksey and O'Malley, 2005). Details are below:

\section{(1) Research questions}

(1) Which overall health indicators could be used to represent health in a place, (2) What geographic boundary size(s) could be used to represent place when examining population health, (3) Does the indicator represent health for all ages in a population and (4) Where the health indicator data can be obtained.

\section{(2) Identifying relevant studies}

Publications were identified by searching three electronic databases for publication years 2010-2020: Ovid Medline and Scopus for journal articles and Google Scholar for grey literature (e.g., public health reports) in English. First, ETM developed and modified the search strategy for Ovid Medline (Supplementary Table S1) in discussion with JH, PN and NS. Three concepts of 'health indicator', 'population assessment' and 'OECD countries' were used to only identify studies where health indicators had been used to assess health at a population-level for the 38 countries currently members of the OECD (OECD, 2021). The OECD search filter was adapted from the Canadian Health Libraries Association (CHLA, 2018).

To evaluate the search strategy, a random 100 publications from the Ovid MEDLINE database were independently screened by ETM and JH based on title and abstract. Reasons for exclusion included the following: (1) the study was not conducted in an OECD country, (2) there was no overall health indicator available (e.g., only a component of health, a health behaviour or syndromic surveillance), (3) no population-level assessment of the health indicator (e.g., sub-group assessment only, only one local area) and/or (4) no data assessed (e.g., editorial).

ETM then applied the agreed search strategy to the remaining Ovid Medline search results, the Scopus search (see Supplementary Table 2) and to the Google Scholar search (see Supplementary Table S3). Endnote X10 was used to import and manage all publications. For Google Scholar, the search interface necessitated conducting each combination of key words within the 'health indicator' and 'population assessment' concepts separately. This resulted in only titles being screened within each of the 15 initial searches. Abstracts were screened separately after records were imported and merged into Endnote.

\section{(3) Study selection}

Next, all articles selected by title and abstract were assessed for further eligibility by full-text assessment. Due to the difficulty of assessing abstracts for whether health indicators are publicly available at a sub-national geographic level, the geographic criteria were only applied at this stage. Identified study websites were also visited to check for updated information.

In addition to a traditional literature search, we conducted key word searches using the internet search engine Google to identify Englishlanguage pages on statistical institutes, national public health institutes and health ministry websites of the 38 members of the OECD countries. Initially, each website was assessed for availability of overall health indicators, followed by whether health indicators were available at sub-national geographic levels.

\section{(4) Data Extraction}

Extracted data included studies and data sources were extracted in a uniform manner. We extracted the following information: country, data source, data collected year(s), number of indicators, how indicators were measured, the geographic levels at which indicators were available and reference information (i.e., citation information for publications and hypertext links for statistical agency data). Notes were kept on whether data fed into other data sources (e.g., national health surveys that are a part of the European Health Examination Survey). Data were extracted by one reviewer (ETM) and a second reviewer (JH) performed an independent data extraction for a randomly chosen $10 \%$ of publications $(n=6)$. Inconsistent results were discussed, and the extraction modified accordingly.

\section{Results}

For the initial literature review, we identified 59 publications (flow chart in Fig. 1, full list of references in Supplementary materials). At the title/abstract screening stage ( $n=1157$ non-duplicates), the most common reasons for exclusion was the health indicator(s) did not cover overall health $(n=459)$ (e.g. a health component indicator, a health behaviour indicator, etc.) or the overall health indicator was not available at a population level $(n=303)$ (e.g. assessed sub-population groups only, only assessed one locality, etc.), followed by the publication being an editorial piece only $(\mathrm{n}=95)$, data not available in an OECD country $(n=71)$ and no full text available to review $(n=18)$ (e.g. conference 


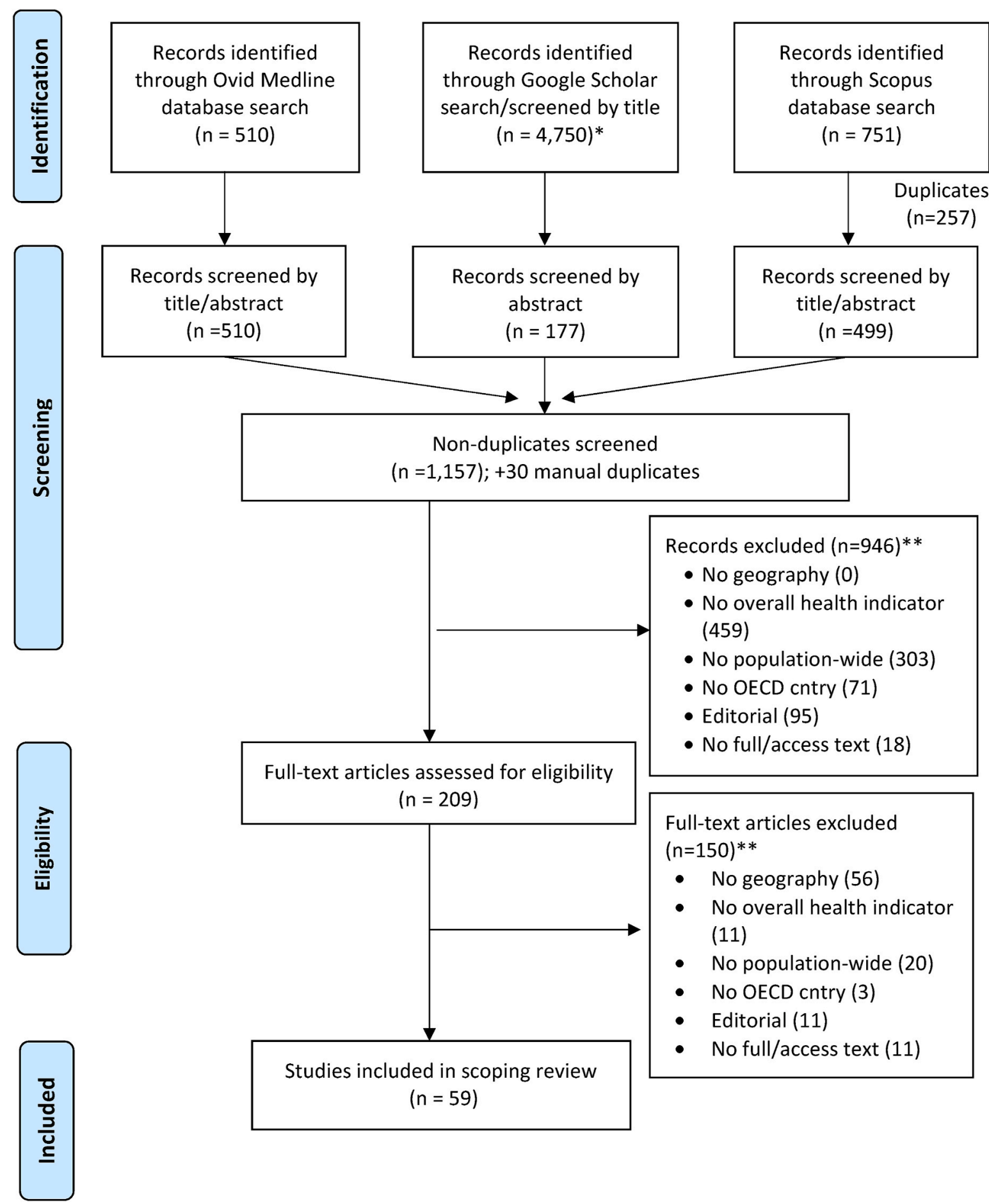

Fig. 1. Flow Diagram for selection of scoping review articles (2010-2020)

16 separate searches. Not mutually exclusive. See Supplementary file 3.

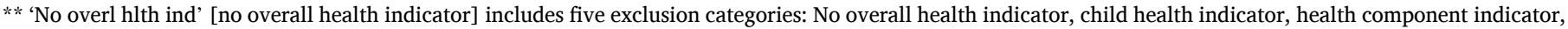

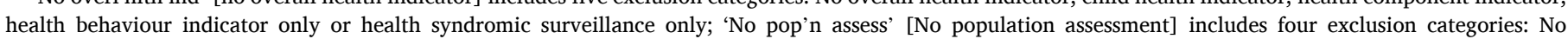
population-wide health assessment, too local, assesses sub-population group only or only associations assessed.

presentation abstract only). For the 210 full texts reviewed, a third (56 out of 150) were excluded for the health indicators not having been available at a sub-national geography. The remaining exclusions were distributed similarly at the title/abstract screening stage.

For almost all OECD countries, except for Chile, additional information on overall health indicator data was available either on the country's statistical agency or public health institute English-language section(s) of their website(s). For studies that had been identified during the literature review, study websites were assessed for further information. Specific information on where health indicator data were identified for each country are located in Supplementary Table 4. For all countries investigated, a comprehensive understanding of available health indicators could not be obtained by academic search engines alone. Even when a specific data source was used in a study (e.g., mortality records or a Health Interview Survey), additional information could usually be found on the specific country or study website. 


\subsection{Health indicators by data source}

Mortality and morbidity indicators were generally obtained from different sources, so will be presented separately.

Table 1 summarizes which mortality indicators were available at a population level below country-level, including the health indicator data source, year(s) of data collection and geographic data boundar(ies) the mortality indicators were available. For the 38 OECD countries, all mortality indicators were available by governmental statistical or public health institutes. The timeframe and years of data collection were highly variable by country. Six organisations or studies compiled all-cause mortality data for sub-national geographic boundaries across multiple countries: OECD.stat (38 countries) for TL2 and TL3 boundaries (Kim, 2019), Euro stat Weekly deaths (28 countries) (Weber and Clerc, 2017) and EURO-HEALTHY (28 countries) (Costa et al., 2019a, 2019b; Freitas et al., 2018; Santana et al., 2020) for NUTS 2 regions, EURO-URHIS2 (14 countries) (de Gelder et al., 2017; Koster et al., 2017; Pope et al., 2017) for project-specific urban areas, and WHO European Healthy cities (all European countries) (de Leeuw et al., 2015). EURO-HEALTHY also compiles cause-specific mortality, life expectancy at birth and amenable/preventable mortality for 28 European regions (Costa et al., 2019a, 2019b; Freitas et al., 2018; Santana et al., 2020), while EURO-URHIS2 only additionally calculates cause-specific mortality for their specified urban areas (de Gelder et al., 2017; Koster et al., 2017; Pope et al., 2017). The EuroMOMO study releases regional-level excess mortality data for 24 European countries, calculated from each country's weekly official national mortality statistics (EuroMOMO, 2021; Kanieff et al., 2010).

For morbidity indicators, 37 OECD countries (excluding Israel) were available in English for sub-national geographies, but varied widely by data source, timescale of data availability, age range of the sample, morbidity indicator and geographic scale. Therefore, Table 2 summarizes sub-national geographic data availability for each OECD country by data source category. Again, a number of studies - EURO-HEALTHY, EU-SILC, EHIS and EURO-URHIS - had morbidity indicator data available for multiple European countries for sub-national geographies; generally for regions, municipalities and/or urban areas (Costa et al., 2019a, 2019b; de Gelder et al., 2017; Freitas et al., 2018; Gray et al., 2012; HintzPeter et al., 2019; Koster et al., 2017; Pope et al., 2017; Santana et al., 2020). For non-European OECD countries, and additional data collection by European countries, morbidity indicator data were available by other Health Interview Surveys (i.e., not a part of EURO-HEALTHY, EU-SILC, EHIS or EURO-URHIS), Health Examination Surveys, Other (not necessarily health) surveys and/or Censuses (see Supplementary Table 4). Within these additional surveys, health indicator availability at sub-national geographies varied considerably. See Supplementary Table 5 for availability of each morbidity indicator, and associated sub-national geographic scale, for each country's specific data source.

\subsection{Health indicators by geographic level frequency}

Table 3 summarizes the frequency that health indicators were identified at sub-national geographies across OECD countries. For example, only one country was identified to have NUTS 1 (major socioeconomic regions) (Eurostat, 2021a) geographic level data on all-cause mortality, cause-specific mortality, life expectancy at birth, life expectancy at age 65 years and disability. In contrast, 26 OECD countries had data on self-rated health, long-standing illness and activity limitation at the same aggregate geographic level. Overall, 'region (NUTS 2)' (basic regions for the application of regional policies) (Eurostat, 2021a) was the most common geographic boundary where health indicator data were available, with three of the eight identified health indicators for all 38 OECD countries, six of the twelve identified indicators having data available for 26 countries, two indicators (cause-specific mortality and healthy life expectancy) available for 24 countries and one indicator (excess mortality) available for 20 countries. The second most frequent geographic level was 'urban area', with data from 24 countries for five health indicators (23 for long-standing illness). Health indicator data were also available frequently at 'municipality' level, with nine of the indicators available at this geographic level for a low of seven, and high of 14, OECD countries. Health indicator data below municipality, or equivalent geographic size, and at any geography for life expectancy at age 65 years, were sparse. For a listing of sub-national geographic availability for specific OECD countries, see Supplementary Table 6.

\subsection{Health indicators by population age}

Of the 12 health indicators identified in this review, only one, life expectancy at age 65 , addressed a specific age range. This indicator was only available at sub-national geographies for six of the OECD countries: Canada (Province/Territory, Public Health Region and Public Health Unit), France (Region: NUTS $1 / 2 / 3$ ), Italy (Region, Prince and Municipality), Japan (City and Prefecture), Portugal (NUTS 3) and the UK (Region NUTS 2, Local Authority, Clinical Commissioning Group and Health Board) (see Supplemental Table 6). Except for life expectancy at age 65 , sub-national mortality data generally represented the entire age range of the population. For sub-national morbidity indicators, the age range varied by, and within, the data source. Health indicators from census data covered the entire population. Some surveys would cover the entire age range of the population, while others only covered an 'adult' population, but the age where adulthood began mostly ranged from age 15 to 25 years. Exceptions were the Canadian Community Health Survey (CCHS), age range 12+, and the Spanish Instituto Nacional de Estadistica (INE), with an age range 9+. We only identified one study with sub-national health indicator data only for older people (age 60+): Columbia's Survey on Health, Well-being and SAlud (SABE) (see Supplementary Table 5).

\section{Discussion}

In this comprehensive scoping review of academic journal articles, grey literature and government statistical \& public health websites, health indicator availability in English for sub-national geographies was limited in both number, data source and geographic scale. Across the 38 OECD countries, only twelve overall health indicators were available at a population level for sub-national geographies, seven mortality and five morbidity. Region, or equivalent large subnational entities, was the predominant geographic level for both mortality and morbidity indicators. Health indicator availability at smaller geographies was sparse, and varied considerably by geographic definition, health indicator, age range of population and years available. In all cases, geographic boundaries used only administrative definitions.

The finding that only a dozen health indicators were available at any sub-national geographies is most likely a result of several cross-national initiatives to harmonize health indicators at larger geographies. Historically, this included the World Health Organization's (WHO) framework for recorded causes of death and Health for All Programme, plus health indicator data collections by the OECD and Eurostat. The European Union has conducted a series of health indicator harmonisation projects, starting with the Amsterdam Treaty in 1993 and continuing through jointly agreeing to a shortlist of indicators in the mid-2000s and the Joint Action for ECHIM in 2009 (Aromaa, 2012). In 2017, experts nominated by EU Member States agreed a set of 40 health indicators for a Joint Monitoring Framework (JMF), which would be used to measure achievement of the Sustainable Development Goals (SDGs), Health 2020 and the Global Action Plan for the Prevention and Control of Non-communicable Diseases (NCDs) (WHO, 2018b). Of these, four reflect overall health: life expectancy at birth, life expectancy at 65, healthy life expectancy and general mortality.

Why regions, (specifically the NUTS 2 definition), is the most frequent geographic boundary available for health indicators, is almost 
Table 1

Health indicators available in OECD countries ${ }^{\text {a }}$ by sub-country geographies: mortality.

\begin{tabular}{|c|c|c|c|c|c|c|c|c|}
\hline Country & Health indicator data source & $\begin{array}{l}\text { Year's data } \\
\text { available }\end{array}$ & $\begin{array}{l}\text { All- } \\
\text { cause }\end{array}$ & $\begin{array}{l}\text { Cause- } \\
\text { specific }\end{array}$ & $\begin{array}{l}\text { Life Exp. } \\
\text { birth }\end{array}$ & $\begin{array}{l}\text { Life } \\
\text { Exp. } \\
65 y\end{array}$ & $\begin{array}{l}\text { Excess (E) } \\
\text { /Preventable (P)/ } \\
\text { Amenable (A) }\end{array}$ & $\begin{array}{l}\text { Geographic data boundary } \\
\text { available }\end{array}$ \\
\hline \multirow{2}{*}{$\begin{array}{l}\text { Europe }(28 \\
\text { countries) }\end{array}$} & Eurostat Weekly deaths & $2000-2020$ & $\checkmark$ & & & & & Region (NUTS 3) \\
\hline & EURO-HEALTHY & 2000-2015 & $\checkmark$ & $\checkmark$ & $\checkmark$ & & $\mathrm{P} / \mathrm{A}$ & $\operatorname{Re}^{c}$ ion (NUTS 2)/Metro. Areas \\
\hline $\begin{array}{l}\text { Europe }(24 \\
\text { countries) }\end{array}$ & EuroMOMO & 2008-2018 & & & & & $\mathrm{E}$ & Region \\
\hline $\begin{array}{l}\text { Europe }(14 \\
\text { countries) }\end{array}$ & EURO-URHIS2 & 2010-2011 & $\checkmark$ & $\checkmark$ & & & & Urban area (project defined) \\
\hline Europe (all) & WHO Healthy Cities & 2009-2013 & $\checkmark$ & & & & & City \\
\hline Australia & NMD & 1964-2018 & $\checkmark$ & $\checkmark$ & $\checkmark$ & & $\mathrm{P}$ & Region/PHN areas/Stat. Area 3 \\
\hline Austria & Statistics Austria & 1970-2019 & $\checkmark$ & & & & & Region/Province \\
\hline Belgium & StatBel & $2009-2020$ & $\checkmark$ & $\checkmark$ & $\checkmark$ & & & Region/Province/District ${ }^{\mathrm{d}}$ \\
\hline Canada & CVSD & 1921-2017 & $\checkmark$ & $\checkmark$ & $\checkmark$ & $\checkmark$ & $\mathrm{P}$ & $\begin{array}{l}\text { Province/Territory/Health } \\
\text { region/Public health unit }\end{array}$ \\
\hline Czech Republic & Czech Statistical Office & 2007-2019 & $\checkmark$ & $\checkmark$ & & & & Regions/Districts (LAU1) \\
\hline Denmark & Statistics Denmark & $2006-20^{\mathrm{e}} 9$ & $\checkmark$ & $\checkmark$ & $\checkmark$ & & & Region/Province/Municipality \\
\hline Estonia & Statistics Estonia & 1989-2016 & $\checkmark$ & & $\checkmark$ & & & Region/County \\
\hline Finland & Cause of Death Register & 1969-2019 & $\checkmark$ & $\checkmark$ & & & & $\begin{array}{l}\text { Region/Municipality } \\
(>20,000)\end{array}$ \\
\hline France & INSEE & 1901-2015 & $\checkmark$ & $\checkmark$ & $\checkmark$ & $\checkmark^{\mathrm{e}}$ & & $\begin{array}{l}\text { Region (NUTS 1/2)/ } \\
\text { Departments (NUTS 3) }\end{array}$ \\
\hline Germany & $\begin{array}{l}\text { Statistisches Bundesamt/ } \\
\text { Max Planck Institute }\end{array}$ & 1910-2019 & $\checkmark$ & $\checkmark$ & $\checkmark$ & & $(P)^{f}$ & Region/Lander/Local districts ${ }^{f}$ \\
\hline Greece & Hellenic Statistical Agency & 1984-2018 & $\checkmark$ & $\checkmark$ & $\checkmark$ & & & ${ }_{\mathrm{g}}$ Region (NUTS 2/3)/Prefecture \\
\hline Hungary & KSH & $2011-2020$ & $\checkmark$ & $\checkmark$ & & & & Region/County \\
\hline Iceland & Statistics Iceland & 1981-2019 & $\checkmark$ & & & & & Municipality \\
\hline Ireland & Central Statistics Office & 2007-2019 & $\checkmark$ & $\checkmark$ & $\checkmark$ & & & Region \\
\hline Israel & CBS & 2017 & $\checkmark$ & & & & & District/Sub-district \\
\hline Italy & Istat & 1990-2018 & $\checkmark$ & $\checkmark$ & & $\checkmark$ & & $\begin{array}{l}\text { Region/Province/Municipality } \\
\mathrm{h}\end{array}$ \\
\hline Japan & Statistics Bureau of Japan & 2009-2019 & $\checkmark$ & $\checkmark$ & $\checkmark$ & $\checkmark$ & & City/Prefecture \\
\hline Latvia & CSB & 1967-2019 & $\checkmark$ & & $\checkmark$ & & & Region/City/County ${ }^{\mathrm{i}}$ \\
\hline Lithuania & Statistics Lithuania & 2019 & $\checkmark$ & $\checkmark$ & & & & Region/County \\
\hline Mexico & INEGI & 2010-2018 & $\checkmark$ & $\checkmark$ & $\checkmark$ & & $\mathrm{E}$ & State \\
\hline The Netherlands & ECHIM & $2011-2013$ & $\checkmark$ & $\checkmark$ & & & $\mathrm{E}$ & Region \\
\hline New Zealand & Stats NZ & 1991-2019 & $\checkmark$ & & $\checkmark$ & & & $\begin{array}{l}\text { Region/District/Health board/ } \\
\text { Local board }\end{array}$ \\
\hline Norway & NIPH & $1990-2018$ & $\checkmark$ & & $\checkmark$ & & & Region/County/City \\
\hline Poland & Statistics Poland & 2003-2019 & $\checkmark$ & $\checkmark$ & $\checkmark$ & & & Region \\
\hline Portugal & INE & 2008-2018 & $\checkmark$ & & $\checkmark$ & $\checkmark$ & & $\begin{array}{l}\text { Region (NUTS 3)/municipality/ } \\
\text { Parish }\end{array}$ \\
\hline Slovak Republic & $\begin{array}{l}\text { Statistical Office of the } \\
\text { Slovak Republic }\end{array}$ & 1994-2019 & $\checkmark$ & $\checkmark$ & & & & $\begin{array}{l}\text { Region (NUTS 3)/District (LAU } \\
\text { 1)/municipality (LAU2) }\end{array}$ \\
\hline Slovenia & $\begin{array}{l}\text { Statistical Office of the } \\
\text { Republic of Slovenia }\end{array}$ & 1995-2019 & $\checkmark$ & & $\checkmark$ & & & Region/municipality ${ }^{j}$ \\
\hline Spain & INE & 1996-2017 & $\checkmark$ & $\checkmark$ & $\checkmark$ & & & $\begin{array}{l}\text { Region/Autonomous } \\
\text { Community/Municipality }{ }^{\mathrm{k}}\end{array}$ \\
\hline South Korea & KOSIS & 1983-2018 & $\checkmark$ & $\checkmark$ & & & & Province \& City/District \\
\hline Sweden & $\begin{array}{l}\text { Statistics Sweden/ } \\
\text { Socialstyrelsen }\end{array}$ & 1968-2019 & $\checkmark$ & $\checkmark$ & $\checkmark$ & & & Region/County $^{1}$ \\
\hline Switzerland & FSO & 1969-2020 & $\checkmark$ & & & & & $\begin{array}{l}\text { Region/Canton/District/ } \\
\text { Commune }^{\mathrm{m}}\end{array}$ \\
\hline Turkey & TurkSTAT & 2010-2019 & $\checkmark$ & $\checkmark$ & & & & Region/Sub-region/Province \\
\hline United Kingdom & ONS & 2001-2018 & $\checkmark$ & $J^{\circ}$ & $\sigma^{\circ}$ & $\checkmark$ & $\mathrm{E} / \mathrm{P}$ & $\begin{array}{l}\text { Region/Local Areas/CCGs/ } \\
\text { Health Boards }{ }^{n}\end{array}$ \\
\hline USA & $\mathrm{CDC}$ & 1999-2016 & $\checkmark$ & $\checkmark$ & & & & State/County/City ${ }^{p}$ \\
\hline
\end{tabular}

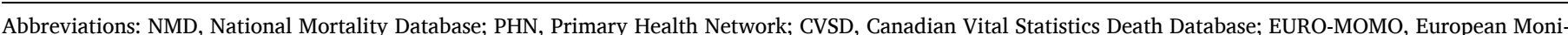

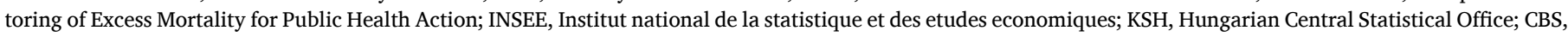

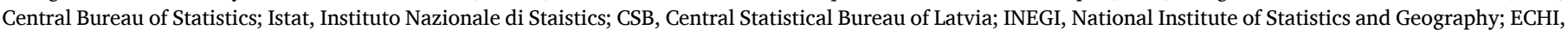

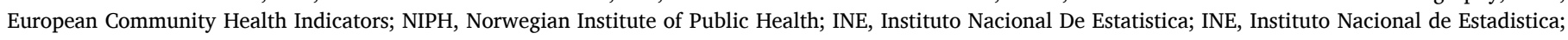

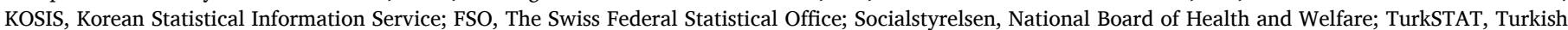
Statistical Institute; ONS, Office for National Statistics; CDC, Centers for Disease Control and Prevention.

${ }^{\text {a }}$ No overall mortality indicator data below country-level identified in English for Chile, Colombia, and Luxembourg.

b Austria, Belgium, Denmark, Estonia, France, Germany, Greece, Hungary, Ireland, Italy, Luxembourg, Malta, Netherlands, Norway, Portugal, Spain, Sweden, Switzerland, and United Kingdom.

c France, Germany, The Netherlands, United Kingdom, Slovenia, Norway, Slovakia, Romania, Former Macedonia, Turkey, Latvia, and Lithuania.

d Cause of death at region level only.

e Life expectancy at 60, not 65, years.

f by Lander (2016)/2018; by Local district avoidable mortality 2000-2008.

g Life expectancy for years 1991-2007 only. See Tsimbos C et al. (2011).

h Elder.stat database of life tables by age 55+ (single and 5-year bands), 2014-2018: Regions, Provinces and Municipalities. All ages region only $1990-2017$. 
${ }^{\text {i }}$ City and county level for all cause only, 2000-2019; life expectancy 2011-2019 only.

${ }^{j}$ Region \& municipality level indicators also available: deaths before 65 years \& premature mortality. Life expectancy at birth available for region only $2011-8$.

${ }^{\mathrm{k}}$ Life expectancy at birth for autonomous community level in 2008 only (Disability, Independence and Dependency Situations Survey).

${ }^{1}$ Cause of death: region 1997-2006; Life expectancy, Region 1998-2002 and 2015-2019; County, 1966-1970 and 2015-2019.

$\mathrm{m}$ Total and excess deaths available weekly, starting in 2020, at region \& canton level, split by two age groups: $<65$ and $65+$ years.

${ }^{\mathrm{n}}$ England and Wales: regions, unitary authorities/counties/districts; Scotland: Council areas; Northern Ireland: Local government districts. Data also acquired from the Northern Ireland Statistics and Research Agency, National Records of Scotland and StatsWales.

${ }^{\circ}$ Cause of death data: administrative areas 2001-2018; life expectancy at birth data: council areas \& NHS Health Boards 1991-1993 and 2016-2018.

p City level is from the 500 Cities Project, with data available 2010-2018 only.

Table 2

Data source(s) for morbidity indicators by country and geographic boundary.

\begin{tabular}{|c|c|c|c|c|c|c|c|c|c|c|}
\hline & EURO-HEALTHY & EU-SILC & EHIS & EHIS2 & E-URHIS & E-URHIS2 & Other HIS & HES & Other Survey & Census \\
\hline Australia & & & & & & & $\mathrm{S} / \mathrm{T}$ & & & Many \\
\hline Austria & R2 & R1 & R2 & R2 & UA & & & & & \\
\hline Belgium & $\mathrm{R} 2 / \mathrm{Mu}$ & R1 & R2 & R2 & UA & & $\mathrm{R} / \mathrm{P}$ & & & \\
\hline Canada & & & & & & & $\mathrm{P} / \mathrm{T} / \mathrm{MA}$ & & $\mathrm{P} / \mathrm{T} / \mathrm{MA}$ & \\
\hline Chile & & & & & & & & $\mathrm{R}$ & & \\
\hline Colombia & & & & & & & & $\mathrm{R}$ & $\mathrm{R}$ & \\
\hline Czech Republic & $\mathrm{R} 2 / \mathrm{Mu}$ & R1 & R2 & R2 & UA & & & & & \\
\hline Denmark & $\mathrm{R} 2$ & R1 & & R2 & UA & & & & & \\
\hline Estonia & R2 & R1 & R2 & R2 & UA & & & & & $\mathrm{R}$ \\
\hline Finland & $\mathrm{R} 2$ & R1 & & R2 & UA & & & $\mathrm{R} / \mathrm{Mu}$ & & \\
\hline France & $\mathrm{R} 2 / \mathrm{Mu}$ & R1 & R2 & R2 & UA & UA & & & & \\
\hline Germany & $\mathrm{R} 2 / \mathrm{Mu}$ & & & R2 & UA & UA & $\mathrm{R} / \mathrm{Mu}$ & $\mathrm{R}$ & $\mathrm{R}$ & \\
\hline Greece & $\mathrm{R} 2 / \mathrm{Mu}$ & R1 & & R2 & UA & & & & & \\
\hline Hungary & $\mathrm{R} 2$ & R1 & & R2 & UA & & & & & $\mathrm{R} / \mathrm{Co}$ \\
\hline Iceland & R2 & R1 & & R2 & UA & & & & & \\
\hline $\begin{array}{l}\text { Ireland } \\
\text { Israel }\end{array}$ & $\mathrm{R} 2$ & R1 & & $\mathrm{R} 2$ & UA & & & & & R/Co/City \\
\hline Italy & $\mathrm{R} 2 / \mathrm{Mu}$ & R1 & & R2 & UA & & & & $\mathrm{Mu}$ & \\
\hline Japan & & & & & & & & & Prefecture & \\
\hline Korea & & & & & & & Co/Di/City & & & \\
\hline Latvia & R2 & R1 & R2 & R2 & UA & UA & & & & \\
\hline Lithuania & R2 & R1 & & R2 & UA & UA & & & $\mathrm{R} / \mathrm{Co}$ & \\
\hline Luxembourg & R2 & R1 & & R2 & & & & & & \\
\hline Mexico & & & & & & & & Admin $\mathrm{T}$ & & \\
\hline Netherlands & R2 & R1 & & R2 & UA & UA & & & Postcode & \\
\hline New Zealand & & & & & & & R/Di/PHU & & & $\mathrm{R}$ \\
\hline Norway & R2 & R1 & & R2 & UA & UA & & & & \\
\hline Poland & R2 & R1 & & R2 & UA & & & & & \\
\hline Portugal & $\mathrm{R} 2 / \mathrm{Mu}$ & R1 & & R2 & & & & $\mathrm{R} / \mathrm{UA}$ & & \\
\hline Slovak Republic & $\mathrm{R} 2$ & R1 & & R2 & UA & UA & & & R2 & \\
\hline Slovenia & R2 & R1 & R2 & R2 & UA & UA & & & & \\
\hline Spain & $\mathrm{R} 2 / \mathrm{Mu}$ & R1 & & R2 & UA & & $\mathrm{AC} / \mathrm{Mu}$ & & & \\
\hline Sweden & $\mathrm{R} 2 / \mathrm{Mu}$ & R1 & & R2 & UA & & & & & \\
\hline Switzerland & $\mathrm{R} 2$ & R1 & R2 & & & & & & & \\
\hline Turkey & & R1 & R2 & & UA & UA & & & & \\
\hline United Kingdom & $\mathrm{R} 2 / \mathrm{Mu}$ & $\mathrm{R} 1$ & & R2 & UA & UA & R/LA/HB & $\mathrm{R}$ & $\mathrm{R}$ & $\mathrm{LA} / \mathrm{OA} / \mathrm{DZ}$ \\
\hline United States & & & & & & & Many & & State/Co/Ma/Mi & Many \\
\hline
\end{tabular}

Abbreviations: AU, Autonomous Community; Co, County; Di, District; DZ, Data Zone; HB, Health Board; HES, Health Exam Survey; HIS, Health Interview Survey; LA, Local Authority; MA, Metropolitan Area; Mu, Municipality; P, Province; PHU, Public Health Unit; R, Region not NUTS or unspecified; R1, Region NUTS 1; R2, Region NUTS 2; OA, Output Area; T, Territory; UA, Urban Area.

${ }^{a}$ A total of 540 municipalities of ten European metropolitan areas: Athens, Barcelona, Berlin, Brussels, Lisbon, London, Paris, Prague, Stockholm, and Turin.

surely due to the ISARE (Health Indicators in the European Regions) projects, who led the collection and harmonisation of health indicator data at NUTS 2 regional levels (Wilkinson et al., 2008). In addition, in the EU the NUTS 2 level designation is used by the EU Commission to allocate funds (Becker et al., 2010; Costa et al., 2019a). The importance of these regions as political and administrative units (Becker et al., 2010), particularly for healthcare funding and planning, would similarly explain why health indicators are routinely collected at similar large sub-national geographies in other non-European countries (e.g. States in USA, Provinces/Territories in Canada, etc.) (Ma and Economic Development Institute (Washington D.C.). Macroeconomic Management and Policy Division., 1997).

Why health indicator data are not more frequently available at smaller, and/or non-administrative geographic scales is complex. Allcause mortality is available at 'a' local geographic level for most OECD countries, but the population size and/or spatial size of these local areas varies widely. Indicators of cause-specific mortality, life expectancy at birth and particularly life expectancy at age 65 at smaller geographies could be mostly calculated from the same data sources of allcause mortality (ONS, 2019). Reasons for unavailability include issues of data access, staff capacity, prioritization and/or perceived usefulness of data. For morbidity indicators, the most likely explanation is a lack of many national surveys to sample sufficient participants at a local level to produce reliable local estimates (Gray et al., 2012). Potential solutions include using only highly-dense geographic units (Gray et al., 2012), increasing sample sizes in national surveys to be locally representative (such as the Korean Community Health Survey Profiles (Kang et al., 2015)), introduce more health questions into national censuses and/or develop new potential big data technologies, such as electronic health records (Carmichael et al., 2017).

The lack of sub-national health indicators or data sources for specific age groups is concerning. The appropriate health indicator to use to 
Table 3

Summary of overall health indicator availability by OECD country and sub-country geography.

\begin{tabular}{|c|c|c|c|c|c|c|c|c|c|c|c|c|}
\hline & \multicolumn{7}{|c|}{ Mortality Indicators } & \multicolumn{5}{|c|}{ Morbidity Indicators } \\
\hline & $\begin{array}{l}\text { All- } \\
\text { cause }\end{array}$ & $\begin{array}{l}\text { Cause- } \\
\text { specific }\end{array}$ & $\begin{array}{l}\text { Life } \\
\text { Exp } \\
\text { birth }\end{array}$ & $\begin{array}{l}\text { Life } \\
\text { Exp } \\
65 y\end{array}$ & Preventable & Excess & Amenable & $\begin{array}{l}\text { Self- } \\
\text { rated } \\
\text { health }\end{array}$ & $\begin{array}{l}\text { Long- } \\
\text { standing } \\
\text { illness }\end{array}$ & $\begin{array}{l}\text { Activity } \\
\text { limitation }\end{array}$ & Disability & $\begin{array}{l}\text { Healthy Life } \\
\text { Expectancy }\end{array}$ \\
\hline \multicolumn{13}{|l|}{ Large geographies: } \\
\hline Region (NUTS 1) & 1 & 1 & 1 & 1 & 0 & 0 & 0 & 26 & 26 & 26 & 1 & 0 \\
\hline Region (NUTS 2) & 26 & 24 & 26 & 2 & 26 & 20 & 26 & 26 & 26 & 26 & 26 & 24 \\
\hline $\begin{array}{l}\text { Autonomous } \\
\text { Community } \\
\text { (Spain) }\end{array}$ & 0 & 1 & 0 & 0 & 0 & 0 & 0 & 0 & 0 & 0 & 0 & 0 \\
\hline $\begin{array}{l}\text { Region } \\
\quad \text { (Unspecified) }\end{array}$ & 2 & 1 & 1 & 1 & 1 & 0 & 0 & 2 & 1 & 2 & 0 & 0 \\
\hline $\begin{array}{l}\text { Public Health } \\
\text { Region }\end{array}$ & 0 & 1 & 1 & 1 & 1 & 0 & 0 & 0 & 0 & 0 & 0 & 0 \\
\hline Province & 7 & 3 & 1 & 1 & 1 & 0 & 0 & 1 & 0 & 1 & 1 & 0 \\
\hline Territory & 1 & 1 & 1 & 1 & 1 & 0 & 0 & 3 & 2 & 1 & 2 & 0 \\
\hline State & 2 & 2 & 1 & 0 & 0 & 1 & 0 & 2 & 1 & 1 & 2 & 0 \\
\hline \multicolumn{13}{|c|}{ Medium Geographies: } \\
\hline Region (NUTS 3) & 5 & 3 & 3 & 2 & 0 & 0 & 0 & 0 & 0 & 0 & 0 & 0 \\
\hline Sub-Region & 0 & 1 & 0 & 0 & 0 & 0 & 0 & 0 & 0 & 0 & 0 & 0 \\
\hline Prefecture & 2 & 1 & 1 & 1 & 0 & 0 & 0 & 0 & 0 & 0 & 0 & 0 \\
\hline County & 7 & 4 & 4 & 0 & 0 & 0 & 0 & 3 & 1 & 2 & 3 & 0 \\
\hline $\begin{array}{l}\text { Local Authority } \\
\text { (UK) }\end{array}$ & 1 & 1 & 1 & 1 & 1 & 1 & 0 & 1 & 1 & 1 & 1 & 1 \\
\hline $\begin{array}{l}\text { Clinical } \\
\text { Commissioning } \\
\text { Group (UK) }\end{array}$ & 1 & 1 & 1 & 1 & 1 & 1 & 0 & 0 & 0 & 0 & 0 & 0 \\
\hline Metropolitan Area & 0 & 0 & 0 & 0 & 0 & 0 & 0 & 2 & 0 & 2 & 1 & 0 \\
\hline Urban Area & 24 & 24 & 0 & 0 & 0 & 0 & 0 & 24 & 23 & 24 & 0 & 0 \\
\hline City & 5 & 3 & 3 & 1 & 0 & 0 & 0 & 2 & 0 & 1 & 1 & 0 \\
\hline District & 6 & 4 & 2 & 0 & 1 & 0 & 0 & 2 & 0 & 1 & 0 & 0 \\
\hline Municipality & 14 & 13 & 11 & 1 & 9 & 1 & 10 & 11 & 11 & 7 & 10 & 2 \\
\hline Commune & 0 & 1 & 0 & 0 & 0 & 0 & 0 & 0 & 0 & 0 & 0 & 0 \\
\hline \multicolumn{13}{|l|}{ Small geographies: } \\
\hline $\begin{array}{l}\text { UK Output Area/ } \\
\text { Data Zone (UK) }\end{array}$ & 1 & 0 & 0 & 0 & 1 & 0 & 0 & 1 & 1 & 0 & 1 & 0 \\
\hline Public Health Unit & 1 & 1 & 1 & 1 & 1 & 0 & 0 & 0 & 0 & 0 & 0 & 0 \\
\hline $\begin{array}{l}\text { Health Board (NZ/ } \\
\text { UK) }\end{array}$ & 1 & 0 & 1 & 1 & 1 & 1 & 0 & 0 & 0 & 0 & 0 & 0 \\
\hline Census Tract (US) & 0 & 0 & 0 & 0 & 0 & 0 & 0 & 1 & 0 & 0 & 1 & 0 \\
\hline $\begin{array}{l}\text { Census Block Group } \\
\text { (US) }\end{array}$ & 0 & 0 & 0 & 0 & 0 & 0 & 0 & 1 & 0 & 0 & 1 & 0 \\
\hline Postcode & 0 & 0 & 0 & 0 & 0 & 0 & 0 & 1 & 1 & 0 & 0 & 0 \\
\hline Census Block (US) & 0 & 0 & 0 & 0 & 0 & 0 & 0 & 1 & 0 & 0 & 1 & 0 \\
\hline
\end{tabular}

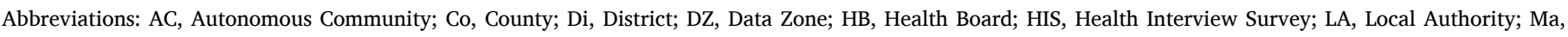

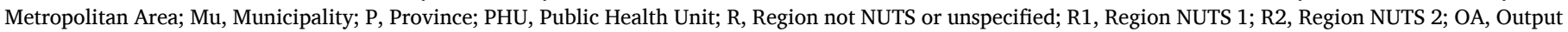
Area; St, State; T, Territory; UA, Urban Area.

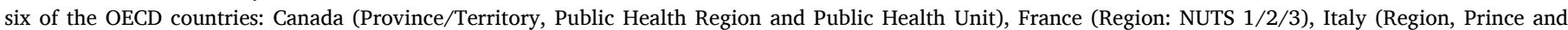

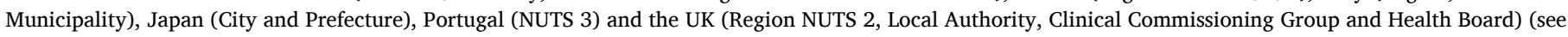
Supplemental Table 6).

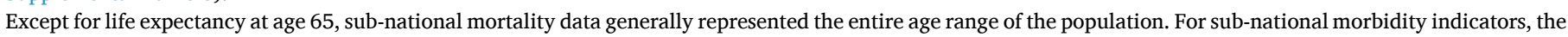

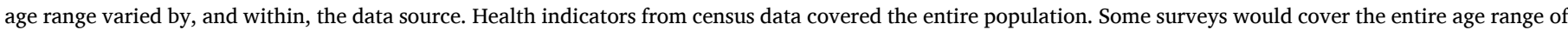

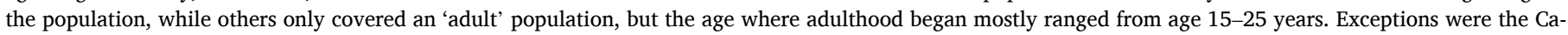

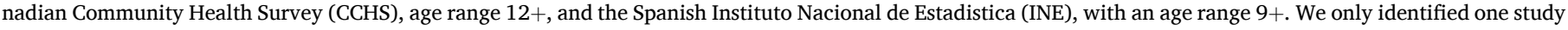

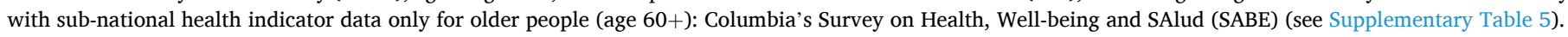

represent a 'healthy' population will vary by the age range of the population. For example, a self-assessment of 'good' health in younger people usually reflects being free of serious disease, while the same rating in older people may reflect that they have less disease than their peers, or than their own health at a previous age (Jylha et al., 2009). The lack of data sources specific to certain age groups with sub-national health indicator data appears to be attributable to most studies being sampled to be only nationally, and not locally, representative. For example, none of the 11 longitudinal ageing studies produce representative health data for sub-national geographies (NIA, 2021). Equally, national surveys with sub-national health indicator data may not have large enough sample sizes in specific age ranges that could be representative and/or released without disclosing personal information of participants.
The main strength of this paper is for the first time creating a summary of overall health indicator data at sub-national geography for over three-dozen countries. The use of varied publication types makes us confident that the review is comprehensive. In particular, assessing research study and statistical agency websites was a valuable activity. Relying on published journal articles alone would have created an incomplete assessment. The largest limitations were to restrict sources to English language and OECD countries. During the search it was apparent that some OECD countries do produce additional publications in nonEnglish languages but it was not possible to determine their content. All non-English-speaking countries also provide English-language versions of their websites. It is, however, unknown if additional information on health indicator data can be found on the non-English websites. We could have contacted representatives from each country, but the 
resources were not available to do so within this project. For the health indicator assessment, we chose to focus on overall, rather than component or behavioural health indicators, as well as adult rather than childhood health indicators. This reflected the decision to not initially exclude publications on geographic criteria, which meant that with each broadening of the concept of health, and increase in age range, the initial search results were excessive. A similar size scoping review could separately be done on each concept of health components, behavioural risk factors, well-being measures and childhood health indicators.

In conclusion, our scoping review provides a comprehensive overview of which health indicators are currently available in English at subnational geographies for all countries in the OECD. The review itself is useful for multiple purposes. The first purpose is to provide a port of call for data analysts to know what population-level health data are available at which sub-national geographies. The second purpose is to highlight gaps in comparative data provision. It is particularly concerning that in the time of a global health crises, that publicly available data on the health of local populations is sparse, comes from limited data sources, only reflects administrative geographic boundaries and is not comparable across countries. We recommend that health monitoring studies be altered and/or new technologies be designed, to allow increased public health monitoring of health at the local level.

\section{Funding}

This work was supported by the Health Foundation.

\section{Declaration of competing interest}

None.

\section{Acknowledgements:}

Thank you to everyone who provided valuable comments on this research, including the HOPE projects, and the Health Foundation's Social and Economic Value of Health Programme, advisory committee members. Thanks also to the anonymous reviewers and editors of Health \& Place.

\section{Appendix A. Supplementary data}

Supplementary data to this article can be found online at https://doi. org/10.1016/j.healthplace.2021.102731.

\section{References}

Arksey, H., O'Malley, L., 2005. Scoping studies: towards a methodological framework. Int. J. Soc. Res. Methodol. 8, 19-32.

Aromaa, A., 2012. Implementation of joint health indicators in Europe - Joint Action for ECHIM. Arpo Aromaa on behalf of the ECHIM core group. Arch. Publ. Health 70, 22 Bambra, C., 2016. Health Divides: where You Live Can Kill You. Bristol University Press. Bambra, C., Smith, K.E., Pearce, J., 2019. Scaling up: the politics of health and place. Soc. Sci. Med. 232, 36-42.

Becker, S.O., Egger, P.H., von Ehrlich, M., 2010. Going NUTS: the effect of EU Structural Funds on regional performance. J. Publ. Econ. 94, 578-590.

Bickenbach, J., 2015. WHO's definition of health: philosophical analysis. In: Schramme, T.E.S. (Ed.), Handbook of the Philosophy of Medicine. Springer, Dordrecht, pp. 1-14.

Bilheimer, L.T., 2010. Evaluating metrics to improve population health. Prev. Chronic Dis. 7, A69.

Carmichael, J.M., Meier, J., Robinson, A., Taylor, J., Higgins, D.T., Patel, S., 2017. Leveraging electronic medical record data for population health management in the Veterans Health Administration: successes and lessons learned. Am. J. Health Syst. Pharm. 74, 1447-1459.

CHLA, 2018. OECD Countries Search Filter. Canadian Health Libraries Association. OECD countries search filter. Precision favored on recall. Research strategy developed by Vicky Tessier at the INSPQ then submitted and updated by Mahée Lacourse. Focus on Canada. Ovid Free Vocabulary only.

Costa, C., Freitas, A., Stefanik, I., Krafft, T., Pilot, E., Morrison, J., Santana, P., 2019a. Evaluation of data availability on population health indicators at the regional level across the European Union. Popul. Health Metrics 17, 11.
Costa, C., Santana, P., Dimitroulopoulou, S., Burstrom, B., Borrell, C., Schweikart, J., Dzurova, D., Zangarini, N., Katsouyanni, K., Deboseree, P., Freitas, Â., Mitsakou, C., Samoli, E., Vardoulakis, S., Dell'Olmo, M.M., Gotsens, M., Lustigova, M., Corman, D., Costa, G., 2019b. Population health inequalities across and within european metropolitan areas through the lens of the euro-healthy population health index. Int. J. Environ. Res. Publ. Health 16.

de Gelder, R., Koster, E.M., van Buren, L.P., van Ameijden, E.J.C., Harrison, A., Birt, C.A., Verma, A., 2017. Differences in adults' health and health behaviour between 16 European urban areas and the associations with socio-economic status and physical and social environment. Eur. J. Publ. Health 27, 93-99.

de Leeuw, E., Green, G., Dyakova, M., Spanswick, L., Palmer, N., 2015. European Healthy Cities evaluation: conceptual framework and methodology. Health Promot. Int. 30 (Suppl. 1), i8-i17.

Declich, S., Carter, A., 1994. Public health surveillance: historical origins, methods and evaluation. Bull. World Health Organ. 72, 285-304.

Etches, V., Frank, J., Di Ruggiero, E., Manuel, D., 2006. Measuring population health: a review of indicators. Annu. Rev. Publ. Health 27, 29-55.

EuroMOMO, 2021. EuroMOMO: Methods.

Eurostat, 2021a. Regions and Cities - Overview.

Eurostat, 2021b. Weekly Death Statistics.

Freitas, A., Santana, P., Oliveira, M.D., Almendra, R., Bana E Costa, J.C., Bana E Costa, C. A., 2018. Indicators for evaluating European population health: a Delphi selection process. BMC Publ. Health 18.

Gray, L., Merlo, J., Mindell, J., Hallqvist, J., Tafforeau, J., O’Reilly, D., Regidor, E., Naess, O., Kelleher, C., Helakorpi, S., Lange, C., Leyland, A.H., 2012. International differences in self-reported health measures in 33 major metropolitan areas in Europe. Eur. J. Publ. Health 22, 40-47.

Hill, A., Balanda, K., Galbraith, L., Greenacre, J., Sinclair, D., 2010. Profiling health in the UK and Ireland. Publ. Health 124, 253-258.

HintzPeter, B., Finger, J.D., Allen, J., Kuhnert, R., Seeling, S., Thelen, J., Lange, C., 2019. European health Interview survey (EHIS) 2 - background and study methodology. Journal of Health Monitoring 4, 66-79.

Jokela, M., 2015. Does neighbourhood deprivation cause poor health? Within-individual analysis of movers in a prospective cohort study. J. Epidemiol. Community 69, 899-904.

Jylha, M., Email Jylha, M., 2009. What is self-rated health and why does it predict mortality? Towards a unified conceptual model. Soc. Sci. Med. 69, 307-316 marja, jylha@uta, fi.

Kang, Y.W., Ko, Y.S., Kim, Y.J., Sung, K.M., Kim, H.J., Choi, H.Y., Sung, C., Jeong, E., 2015. Korea community health survey data Profiles. Osong Public Health and Research Perspectives 6, 211-217.

Kanieff, M., Rago, G., Minelli, G., Lamagni, T., Sadicova, O., Selb, J., Vantarakis, A., Conti, S., 2010. The potential for a concerted system for the rapid monitoring of excess mortality throughout Europe. Euro Surveill.: Bulletin Europeen sur les Maladies Transmissibles = European Communicable Disease Bulletin 15 (43).

Kim, K.T., 2019. Revisiting the income inequality hypothesis with 292 OECD regional units. Int. J. Health Serv. 49, 360-370.

Koster, E.M., de Gelder, R., Di Nardo, F., Williams, G., Harrison, A., van Buren, L.P., Lyshol, H., Patterson, L., Birt, C.A., Higgerson, J., Achterberg, P.W., Verma, A., van Ameijden, E.J.C., 2017. Health status in Europe: comparison of 24 urban areas to the corresponding 10 countries (EURO-URHIS 2). Eur. J. Publ. Health 27, 62-67.

Ma, J., Economic Development Institute (Washington D.C.) Macroeconomic Management and Policy Division, 1997. Intergovernmental Fiscal Transfers in Nine Countries: Lessons for Developing Countries. World Bank, Economic Development Institute, Macroeconomic Management and Policy Division, Washington, DC.

Marshall, L., Finch, D., Cairncross, L., Bibby, J., 2018. Briefing: the Nation's Health as an Asset. The Health Foundation.

Medicine, I.o., 1998. Summarizing Population Health. US.

NIA, 2021. Publicly Available Databases for Aging-Related Secondary Analyses in the Behavioral and Social Sciences, GATEWAY TO GLOBAL AGING DATA. National Institute on Aging.

OECD, 2021. OECD: Better Policies for Better Lives.

ONS, 2019. Guide to Calculating National Life Tables: Explanation of the Methodology Used to Create the National Life Tables.

ONS, 2021. Census 2021.

Parrish, R.G., 2010. Measuring population health outcomes. Prev. Chronic Dis. 7, A71.

Petrovic, A., Manley, D., van Ham, M., 2020. Freedom from the tyranny of neighbourhood: rethinking sociospatial context effects. Prog. Hum. Geogr. 44, 1103-1123.

Pope, D., Puzzolo, E., Birt, C.A., Guha, J., Higgerson, J., Patterson, L., van Ameijden, E., Steels, S., Owusu, M.W., Bruce, N., Verma, A., 2017. Collecting standardised urban health indicator data at an individual level for adults living in urban areas: methodology from EURO-URHIS 2. Eur. J. Publ. Health 27, 42-49.

Santana, P., Freitas, Â., Stefanik, I., Costa, C., Oliveira, M., Rodrigues, T.C., Vieira, A. Ferreira, P.L., Borrell, C., Dimitroulopoulou, S., Rican, S., Mitsakou, C., MaríDell'Olmo, M., Schweikart, J., Corman, D., Bana E Costa, C.A., Quintal, C., Malva, J., Cunha, L., Nossa, P., Almendra, R., Fernandes, R.G., Palència, L., Camprubí, L., Rodríguez-Sans, M., Gotsens, M., Vardoulakis, S., Heaviside, C., Tenailleau, Q., Squiban, C., Alvarenga, A., Freitas, L., Correia, P., Ledoux, C., Pilot, E., Krafft, T., Pikhart, H., Morrison, J., Franke, C., Burström, B., Samoli, E., Katsouyanni, K., Rodopoulou, S., Dzúrová, D., Lustigová, M., Cavallo, A., Coué, N., Bosáková, L., Tkáć, M., Vandenheede, H., Deboosere, P., Costa, G., Zengarini, N., 2020. Advancing tools to promote health equity across European Union regions: the EURO-HEALTHY project. Health Res. Pol. Syst. 18.

Shandera, W.X., 2014. The bottom quartile for health indices in America vs Europe Journal of Infection and Public Health 7, 420-426. 
Weber, A., Clerc, M., 2017. Deaths amenable to health care: converging trends in the EU? Health Pol. 121, 644-652.

WHO, 1948. Constitution. World Health Organisation, Geneva.

WHO, 2018a. 2018 Global Reference List of 100 Core Health Indicators (Plus HealthRelated SDGs). World Health Organisation, Geneva.

WHO, 2018b. Developing a Common Set of Indicators for the Joint Monitoring Framework for SDGs, Health 2020 and the Global NCD Action Plan: Meeting of the Expert Group. WHO Regional Office for Europe, Copenhagen Denmark.
WHO, 2018c. International Classification of Functioning, Disability and Health (ICF). World Health Organisation, Geneva.

Wilkinson, J., Berghmans, L., Imbert, F., Ledesert, B., Ochoa, A., 2009. Health indicators in the European regions: expanding regional comparisons to the new countries of the European Union - ISARE III. Publ. Health 123, 490-495.

Wilkinson, J., Berghmans, L., Imbert, F., Ledesert, B., Ochoa, A., team, I.I.p., 2008. Health indicators in the European regions-ISARE II. Eur. J. Publ. Health 18, 178-183. 